\title{
SAUDAÇÃO AO PROFESSOR SÉRGIO PINTO MARTINS NA SOLENIDADE DE POSSE NO DEPARTAMENTO DE DIREITO DO TRABALHO
}

\author{
Nelson Mannrich \\ Professor Titular do Departamento de Direito do \\ Trabalho da Faculdade de Direito da \\ Universidade de São Paulo
}

O Salão Nobre da Faculdade de Direito do Largo de São Francisco está em festa para a posse solene de seu novo Titular de Direito do Trabalho, Professor Sérgio Pinto Martins.

O que significa, para uma tradicional Faculdade de Direito, com quase 200 anos de história, posse solene de um professor titular?

De um lado, significa integrar, de forma solene, a Congregação da Faculdade, com direito a um assento previamente designado, com inscrição do nome do professor, para desempenhar as atribuições estatutárias e usufruir dos privilégios que lhe confere o mais alto posto na carreira docente, junto à Universidade de São Paulo.

Por outro, significa assumir compromissos perante os demais professores, a comunidade acadêmica e a própria Universidade. É o momento em que o novo titular, professando solenemente seus votos, define os objetivos a que se propõe, expondo seus propósitos perante à Congregação, aos alunos e à comunidade.

Daí porque todos aguardamos com ansiedade a manifestação do professor titular Sérgio Pinto Martins, verdadeiro juramento.

Além de professores e alunos, aqui se encontram os familiares do Professor que hoje toma posse. Mais do que ninguém, sua mãe, a Dona Clarice, sabe dos caminhos árduos e difíceis que seu filho percorreu para hoje estar aqui. Seu velho companheiro e pai, o Seu Rubens, de saudosa memória, teria orgulho de poder estar aqui - mas não está? - para testemunhar a trajetória de seu pequeno/grande herói.

Sua mulher, Dra. Márcia, e sua filha, Mariana, também têm justo motivo para ter orgulho do marido e pai que hoje toma posse, pelo companheirismo e lições de vida.

Mas, quem é o Sérgio, esse jovem que até hoje surpreende a todos pela sua carreira fulminante, seja como juiz, seja como professor ou escritor? 
Filho único de pais descendentes de italianos e portugueses - ainda garoto, gostava de assistir a jogos de futebol - parece que o sangue italiano foi decisivo na escolha do Palmeiras, seu time preferido. Adorava passar suas férias em Santos.

Bem cedo, apreendeu a disciplina do trabalho, com seu saudoso pai, que lhe transmitiu os segredos do ofício de contador. Com 14 anos, freqüentando de manhã o colégio estadual Professor Antônio Alves Cruz, na parte da tarde ajudava o Sr. Rubens na difícil tarefa de copiar livros diários, fazendo a escrituração contábil dos mais de 100 clientes do escritório de contabilidade. As vezes, levava o serviço para casa, sendo que, não raro, trabalhava nos fins de semana.

Seu contato com o escritório de seu pai influenciou-o, depois, a fazer o Curso Superior de Contabilidade, na Álvares Penteado - hoje FACESP - Faculdade de Ciências Econômicas de São Paulo e o de Ciências Administrativas, na Faculdade de Ciências Econômicas e Administrativas da Universidade Mackenzie. No pós-graduação, obteve título de mestre em Direito Tributário.

Quando aluno na Álvares Penteado, nos seis primeiros meses, cursour no prédio aqui ao lado da Faculdade, no Largo de São Francisco.

Além disso, fez o curso de Direito, na Universidade Mackenzie - tendo concluído Contabilidade em 1984, no curso noturno e, Direito, em 1985, no curso diurno.

Em 1986, concluiu o curso de especialização em Direito Empresarial, no Mackenzie.

Matriculou-se no curso de Pós-Graduação, aqui no Largo de São Francisco, obtendo o título de Mestre em 1992. Em seguida, obteve o título de doutor em Direito do Trabalho, defendendo, em 21.5.1996, a tese "Contribuição Confederativa". No ano seguinte, em fevereiro de 1997, defendeu a tese "O FGTS em face da Constituição de 1988" que lhe valeu o título de livre-docente, abrindo-lhe as portas para concorrer a professor titular, em maio de 2001, com a tese "O pluralismo do Direito do Trabalho"

Em 10 anos, esse jovem professor fez uma trajetória exemplar, passando de Mestre a professor titular.

Onde o segredo do sucesso dessa carreira? O que moveu esse jovem professor, de forma obstinada e perseverante, a ser o vitorioso que todos admiramos? Ele mesmo responde: é uma questão de oportunidade.

Na sua simplicidade de ver as coisas e enfrentar a vida, tem consciência de que há outros melhores e que o que está em jogo não é o merecimento - apenas soube aproveitar o momento certo: sabia que alguns professores iam se aposentar e, 
inevitavelmente, suas vagas deveriam ser preenchidas por candidatos devidamente titulados.

Mas, como aproveitar a oportunidade? "Faço o melhor possível, nas condições que tenho" - e assim esse gigante do Direito do Trabalho expõe sua filosofia de vida.

Gigante não lhe soa bem, pela sua modéstia. Mas, basta ler os repertórios dos tribunais especializados, para se deparar com um número sem fim de sentenças e acórdãos que citam a doutrina do Professor Titular Sérgio Pinto Martins - inclusive acórdãos do Supremo Tribunal Federal, além da doutrina especializada, que se louva em seus ensinamentos.

Nem poderia ser diferente, eis que o nosso professor já publicou 34 livros, versando matérias de Direito do Trabalho, Previdência Social e Direito Tributário, sendo que três deles já beiram à $20^{*}$ edição. É autor de mais de 10 obras coletivas. Até junho de 2003, publicou 324 artigos. Conferencista dos mais procurados, até junho desse ano participou de 244 palestras, conferências e discursos.

Onde encontra tempo para escrever? É muito simples: todo material que utiliza para as aulas e palestras, transforma em artigo ou livro. E, como esforçado que é - maior virtude que ostenta, segundo ele mesmo - produziu esse acervo jurídico que poucos conseguiram.

Como consegue conciliar sua vida profissional com sua vida pessoal e familiar? Para o futuro, há muitos projetos, mas a construção de sua felicidade ocorre no dia a dia, a cada momento e se sente feliz por fazer o que gosta - tem orgulho de ser professor e, em especial, de ser juiz.

Com efeito, seu tempo não é dedicado apenas à árdua tarefa de escrever livros e artigos. Dedica-se ao magistério, desde 1990, iniciando-se na condição de auxiliar de ensino, na Faculdade de Direito onde se formara, onde permanece até hoje. Mas também leciona aqui, nas Arcadas, onde tem orgulho de ser professor, pois, como lembra, "trata-se da escola mais importante do país"

Além de professor, Sérgio Pinto Martins é Juiz do Trabalho, desde 14.9.90. Como nasceu sua vocação para a magistratura?

Talvez da constatação de que as empresas, em geral, não oferecem segurança e, ao menor sinal de crise, livram-se de seus empregados, intranqüilidade essa ausente na carreira pública. Aliás, isso lhe ocorreu quando, gerente do departamento jurídico do Banco Sistema, com apenas 26 anos, perdeu o emprego de advogado por 
ocasião do Plano Collor, submetendo-se, a partir de então, a concursos, primeiro para Promotor Público, depois, Juiz do Trabalho.

Outras razões o levaram a ser Juiz do Trabalho: no lugar da parcialidade do-advogado, que muitas vezes defende seu cliente mesmo sabendo que não tem razão, sente-se mais confortável dizer o direito com imparcialidade.

Mas, como juiz, prefere o acordo à sentença - muitas vezes a sentença não resolve o problema - cria outro - daí porque se empenha no acordo - mesmo que a sentença seja correta do ponto de vista legal, nunca será tão boa a ponto de substituir o acordo.

Como Juiz, às vezes não consegue distinguir quem está em dificuldade - se o empregado ou a empresa - pois a hipossuficiência não é privilégio apenas do trabalhador.

Consciente dos graves problemas enfrentados pela Justiça do Trabalho e convencido da necessidade da reforma do Direito do Trabalho, Sérgio Pinto Martins daria às Comissões de Conciliação Prévia caráter de Juizado Especial, integradas na Justiça do Trabalho. Com isso, reduziria custos, teriam tais mecanismos mais credibilidade e, o mais importante, sem prejuízo da atual agilidade, com inevitáveis vantagens na redução de conflitos a serem encaminhados à Justiça do Trabalho.

Mas, antes de enfrentar os efeitos - propõe o Professor Sérgio atacar as causas - excesso de leis, com muitos artigos na CLT de duvidosa vigência - daí sua proposta de faxina, limpando a CLT daqueles artigos que perderam seu fundamento em face da Constituição de 1988 ou em razão das mudanças tecnológicas e de informação, especialmente no que se refere ao Direito Coletivo. Trata-se de tarefa simples, conclui, a ser enfrentada inclusive por meio de Medida Provisória.

Outra proposta, de mais difícil execução, consiste em rever nosso modelo de relações de trabalho, mediante implantação do pluralismo sindical, sem prejuízo de uma contribuição negociada, para sustentar o sistema confederativo.

Na sua visão, a reforma passa, ainda, pela extinção do poder normativo: caberia à Justiça do Trabalho apenas a competência para dizer se a greve foi abusiva ou não. Tem consciência de que não há unanimidade entre seus pares, alguns mais preocupados em manter a Justiça do Trabalho - mas o que a mantém é a arrecadação do INSS, IR, além das custas do processo e, naturalmente, a ampliação de sua competência.

Acredita o Professor Sérgio na arbitragem, pelo seu dinamismo - mas há resistências de ordem cultural - o trabalhador prefere a Justiça do Trabalho. 
De qualquer forma, a Justiça do Trabalho deve ser aperfeiçoada, com ampliação de seus quadros e redução de sua burocracia - esse o seu maior desafio, conclui.

Algumas talvez estejam se perguntando: afinal, viemos à posse do Professor Titular Sérgio Pinto Martins, e onde está ele? Porque, ao invés de vir pessoalmente, mandou representante? Não, não estranhem - é ele mesmo que está aqui.

Aliás, essa dificuldade já foi enfrentada muitas vezes pelo nosso homenageado - em geral, diz ele, as pessoas esperam alguém mais velho, já barrigudo e careca. Quando se deparam com esse jovem, simples, direto, de poucas palavras, mas objetivo e franco, ficam surpresos e, às vezes, decepcionados.

Numa conferência na Faculdade de Direito do Sul de Minas, em Pouso Alegre, um aluno, revoltado, volta-se para o coordenador e indaga: "cadê o Sérgio Pinto Martins? Porque mandaram esse moleque para substituí-lo?”

Esse jovem professor, que hoje toma posse como titular de Direito do Trabalho, exibe um pensamento maduro, não conservador. Aplica as lições de Pound, para quem a ordem jurídica deve ser flexível, ao mesmo tempo que estável.

Professor Titular Sérgio Pinto Martins, bem-vindo!! 